\title{
Mass-spectrometric studies of new 6-nitroquipazines—serotonin transporter inhibitors
}

\author{
Janina Witowska-Jarosz • Małgorzata Jarończyk • Aleksander P. Mazurek • \\ Ingebrigt Sylte • Andrzej J. Bojarski • Zdzisław Chilmonczyk • Maciej Jarosz
}

Received: 30 June 2011 /Revised: 24 August 2011 /Accepted: 8 September 2011 /Published online: 1 October 2011

(C) The Author(s) 2011. This article is published with open access at Springerlink.com

\begin{abstract}
Six synthesized 6-nitroquipazine derivatives were examined by electron ionization (EI) and electrospray ionization (ESI) mass spectrometry in positive and negative ion mode. The compounds exhibit high affinity for the serotonin transporter (SERT) and belong to a new class of SERT inhibitors. The EI mass spectra registered in negative ion mode showed prominent molecular ions for all the compounds studied. All EI mass spectra and all ESI mass spectra showed similar fragmentation pathways of molecular ions, but the pathways differed between EI and ESI. The differences were explained with the aid of theoretical
\end{abstract}

Published in the 10th Anniversary Issue.

Electronic supplementary material The online version of this article (doi:10.1007/s00216-011-5410-8) contains supplementary material, which is available to authorized users.

J. Witowska-Jarosz · M. Jarończyk · A. P. Mazurek •

Z. Chilmonczyk

National Medicines Institute,

Chełmska 30/34,

00-725 Warsaw, Poland

I. Sylte

Medical Pharmacology and Toxicology, Department of Medical

Biology, Faculty of Health Sciences, University of Tromsø,

9037 Tromsø, Norway

\author{
A. J. Bojarski \\ Department of Medicinal Chemistry, Institute of Pharmacology, \\ Polish Academy of Sciences, \\ Smętna 12 , \\ 31-343 Cracow, Poland \\ M. Jarosz ( $\square)$ \\ Chair of Analytical Chemistry, Faculty of Chemistry, \\ Warsaw University of Technology, \\ Noakowskiego 3, \\ 00-664 Warsaw, Poland \\ e-mail: mj@ch.pw.edu.pl
}

evaluation of the stability of the respective radical ions (EI MS) and protonated ions (ESI MS).

Keywords Alkylnitroquipazines · Serotonin transporter inhibitors - Semiempirical geometry and charge distribution optimization · Electron ionization mass spectrometry . Electrospray ionization mass spectrometry

\section{Introduction}

The serotonin (5-HT) transporter (SERT), together with dopamine and noradrenaline transporters, belongs to the neurotransmitter sodium symporter family [1]. SERT acts as a cotransporter of sodium and chloride ions, and of 5-HT molecules [2-4]. The human SERT consists of 630 amino acids with putative 12 transmembrane domains and cytoplasmic $\mathrm{N}$ - and C-terminal domains $[5,6]$. SERT is located in the membrane of presynaptic serotonergic neurons and transports the neurotransmitter 5-HT back into the presynaptic neuron after its release into the synaptic cleft [7]. Hence, SERT plays an important role in termination of 5-HT-mediated neuronal signalling.

The transporter is targeted by the tricyclic antidepressant and selective 5-HT reuptake inhibitor (SSRI) classes of antidepressant drugs as well as by psychostimulant compounds such as amphetamines and cocaine. The compounds act by inhibiting SERT, causing increased levels of 5-HT available for interaction with postsynaptic 5-HT receptors [8]. SSRIs are today the most widely used agents for the treatment of depression and many additional neuropsychiatric and related disorders [9]. The SSRIs act by blocking 5-HT reuptake, thus increasing the concentration of 5-HT at the synapse, enhancing the serotonergic neuronal transmission. A variety of SSRIs such as fluoxetine and paroxetine have been 
developed for the treatment of depression [7]. However, there is still a need to identify other modulators of SERT given the large number of neurological and psychiatric diseases associated with transporter defects. The available SSRIs are known to have side effects such as, but not limited to, anxiety, impotency and sleep disorders. However, a major problem with SSRIs is that they have a 2-4-week delayed onset of action [10,11]. Thus, new therapeutic agents are needed that are safer and more effective than known SSRIs.

We synthesized new SERT inhibitors of general structure A shown in Fig. 1a, exhibiting high affinity for the transporter. The compounds were subjected to pharmaco-
Fig. 1 Structures of compounds 1-6 (a) and their fragmentation patterns observed by electron ionization $(E I)$ and electrospray ionization $(E S I)$ mass spectrometry $(M S)$ in positive ion mode (b) a<smiles>CN1CCN(c2ccc3cc([N+](=O)[O-])ccc3n2)CC1</smiles>

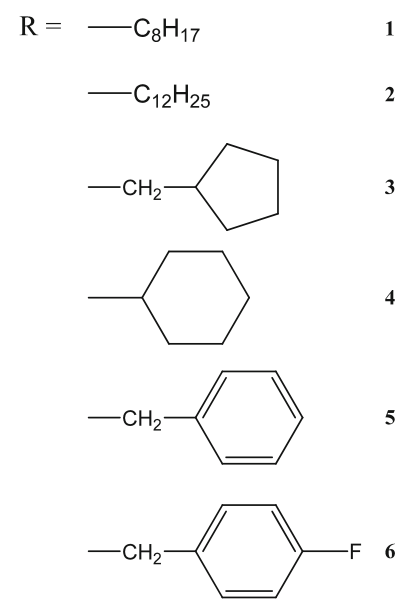

b

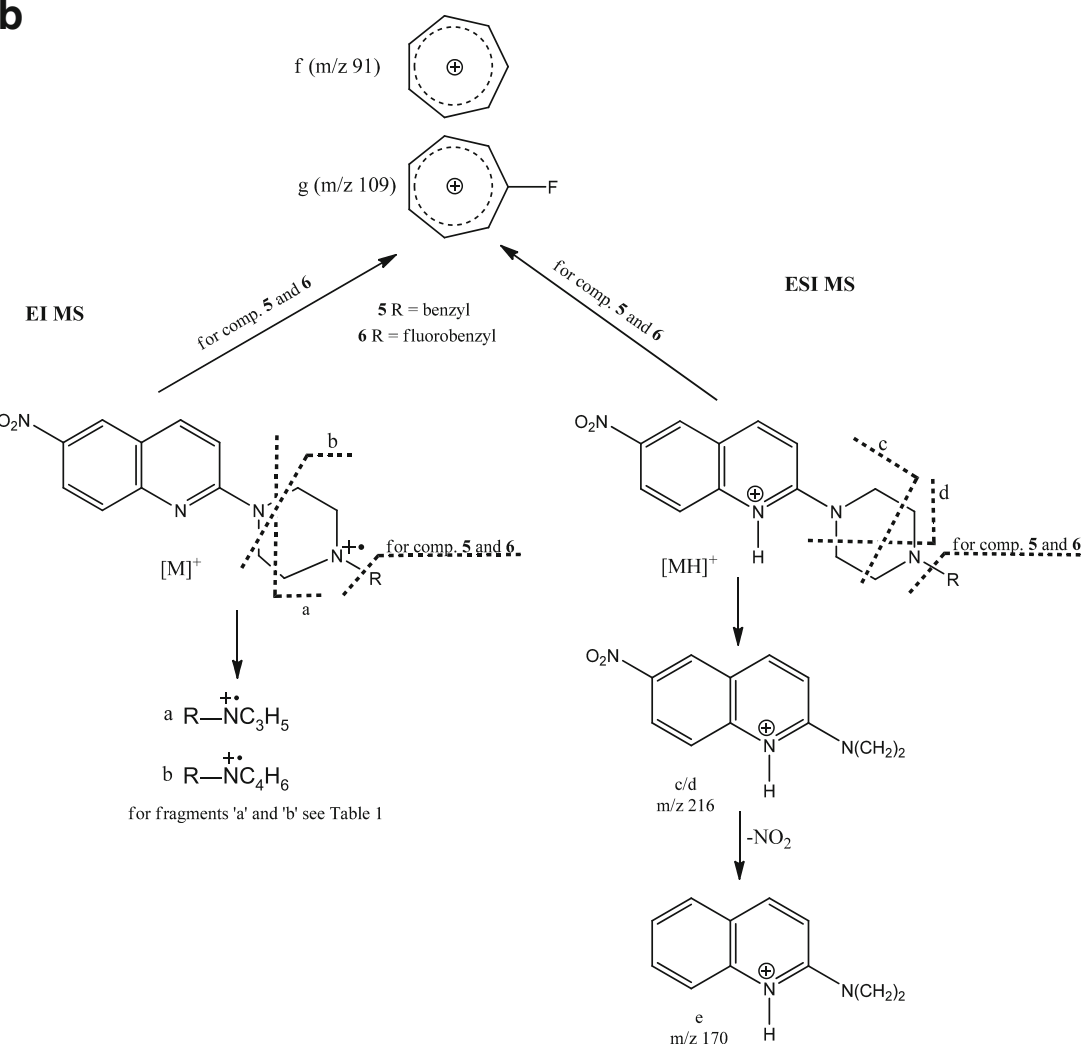


logical tests in vitro and in vivo. Some of them exhibited agonistic activity at presynaptic $5-\mathrm{HT}_{1 \mathrm{~A}}$ receptors as well as antidepressant activity in an animal model of depression (Porsolt test). We have also determined basic parameters that are useful for explanation of the biological activity trends and conducted docking of the compounds to homology-based SERT models [12]. In this work, we examine electron ionization (EI) and electrospray ionization (ESI) mass spectra in positive and negative ion mode of compounds 1-6 in Fig. 1a, exhibiting high affinity for SERT and belonging to a new class of SERT inhibitors.

\section{Experimental}

Mass spectrometry

EI mass spectra were recorded in positive and negative fullscan mode with use of a Finnigan MAT SSQ 7000 single-stage quadrupole mass spectrometer capable of EI, chemical ionization, atmospheric pressure chemical ionization and ESI. A PC running on the X-calibur operating system was used for data acquisition and data processing. The parameters of the EI source were as follows: emission current $1.3 \mathrm{~mA}$, electron
Fig. 2 Mass spectra of 4'-cyclopentylmethyl6-nitroquipazine $\left(3, M_{\mathrm{r}}=340\right.$, $\mathrm{C}_{13} \mathrm{H}_{24} \mathrm{~N}_{4} \mathrm{O}_{2}$ ): EI in positive (top) and negative (middle) ion mode, and ESI MS and ESI MS/MS fragmentation of the protonated molecular ion at $\mathrm{m} / \mathrm{z} 341$ (bottom in frame)
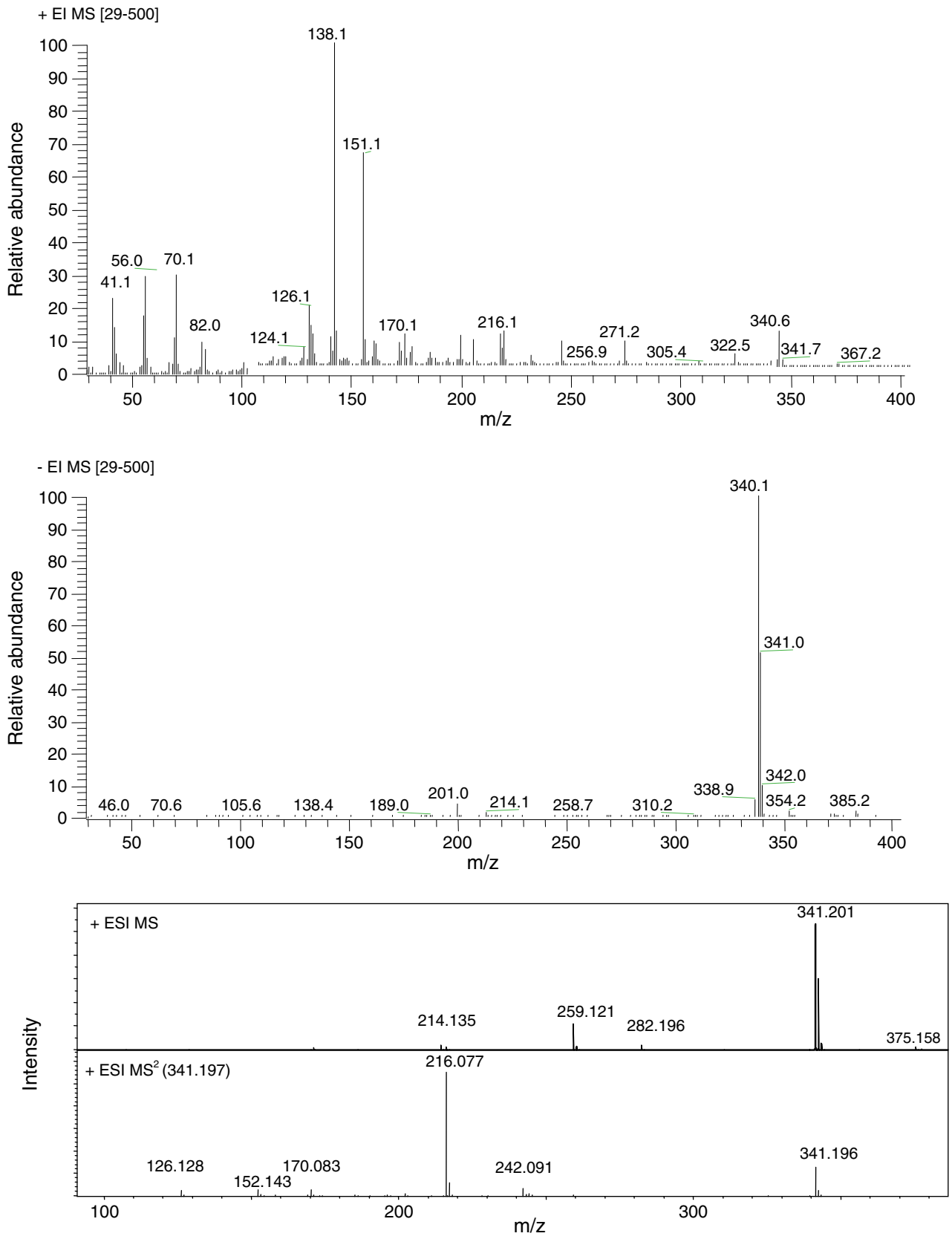
energy $70 \mathrm{eV}$, sample introduction with the aid of a direct-inlet probe.

ESI mass spectra were recorded with the aid of a Bruker Daltonics MicrOTOF-Q II mass spectrometer capable of high-resolution mass spectrometry (MS) and MS/MS. The parameters of the ESI source were as follows: capillary voltage $4,500 \mathrm{~V}$, end plate offset voltage $-500 \mathrm{~V}$, collision energy $20-35 \mathrm{eV}$, nebulizer pressure 0.8 bar, drying temperature $170^{\circ} \mathrm{C}$, dry gas flow rate $8 \mathrm{~L} \mathrm{~min}^{-1}$.

Samples $(2 \mu \mathrm{L}$ in methanol) were injected into the ESI source directly and after separation by an Ultimate 3000 (DIONEX) high-performance liquid chromatography system equipped with a 136/CF column and an auxiliary UV detector $(\lambda=256 \mathrm{~nm})$; the flow rate was $0.15 \mathrm{~mL} \mathrm{~min}^{-1}$. For high-performance liquid chromatography, gradient elution of solvents A $(900: 100: 1 \mathrm{v} / \mathrm{v} / \mathrm{v}$ water-acetonitrile-trifluoroacetic acid) and B (900:100:1 $\mathrm{v} / \mathrm{v} / \mathrm{v}$ methanol-acetonitrile-trifluoroacetic acid) was employed: $0-2$ min $10 \%$ solvent B, 7 min $90 \%$ solvent $\mathrm{B}, 12-14$ min $10 \%$ solvent $\mathrm{B}$.

\section{Theoretical calculations}

The geometry optimization as well as calculation of the charge distribution in the cation radical, and calculation of the relative stability of protonated species of compound $\mathbf{3}$ were performed using the semiempirical AM1 method as implemented in the Spartan'04 program [13].

\section{Results and discussion}

Hard (electron) and soft (electrospray) ionization techniques were used for mass spectrometric studies of new alkylnitroquipazine derivatives exhibiting potential antidepressant activity. The EI spectra of compounds 1-6 (Figs. 2, S1) showed the presence of ions containing substituents $(\mathrm{R})$ with fragments of a piperazine ring $\left(\left[\mathrm{RNC}_{3} \mathrm{H}_{5}\right]^{+}\right.$and $\left[\mathrm{RNC}_{4} \mathrm{H}_{6}\right]^{+}$ (Table 1, Fig. 1b, fragments a and b, respectively). For compounds 1-4, base peaks corresponded to $\left[\mathrm{RNC}_{3} \mathrm{H}_{5}\right]^{+}$ ions, whereas for compounds $\mathbf{5}$ and $\mathbf{6}$ (possessing an aromatic R substituent), base peaks were attributed to benzyl $(\mathrm{m} / \mathrm{z}$ 91) and fluorobenzyl $(\mathrm{m} / \mathrm{z} 109)$ fragment ions (Fig. 1b, fragments $\mathrm{f}$ and $\mathrm{g}$, respectively). The small intensity signals at $\mathrm{m} / z 202$ and 214 corresponded to the ions formed after subtraction of $\left[\mathrm{RNC}_{3} \mathrm{H}_{5}\right]$ and $\left[\mathrm{RNC}_{2} \mathrm{H}_{4}\right]$ from molecular ion moieties, respectively. 6-Nitroquipazine ion, $[\mathrm{M}-\mathrm{R}]^{+}$, was registered at $\mathrm{m} / \mathrm{z} 257$. Typical fragmentation of nitro-groupcontaining aromatic compounds [14] with formation of $[\mathrm{M}-\mathrm{O}]^{+},[\mathrm{M}-\mathrm{NO}]^{+}$and $\left[\mathrm{M}-\mathrm{NO}_{2}\right]^{+}$ions was not observed.

In addition to the usually registered positive ions, negative ions can also be formed during EI (Fig. S2). The efficiency of this process is substantially lower and the lifetimes of the negative ions are shorter (they are more unstable and seldom examined). However, for 6-nitroquipazine derivatives 1-6, strong signals of negative molecular anions $\mathrm{M}^{-}(100 \%$ relative abundance) occurred as a result of thermal electron capture. They can serve as a source of information for the molecular masses of the compounds examined, as the intensity of the molecular ions registered in positive ion mode, $\mathrm{M}^{\cdot+}$, is low (5-20\%) and diminishes with increased length of the aliphatic substituent.

The ions appeared to be relatively stable, since no fragment ions in considerable amounts were registered. The stability of the ions was explained by the presence of a nitro substituent at the aromatic quinoline ring.

The ESI technique in positive ion mode showed mainly protonated molecular ions, $[\mathrm{M}+\mathrm{H}]^{+}$, for all compounds investigated. MS/MS was applied to search for fragmentation of these pseudomolecular ions. For all compounds, mainly fragment ions at $\mathrm{m} / \mathrm{z} 216$ were registered, followed by ions at $\mathrm{m} / \mathrm{z} 170$ (Figs. 2, S3). Exact mass measurements were performed to confirm the elemental composition of each ion registered.

Table 1 Electron ionization mass spectrometry: positive fragment ions of 4'-R-substituted 6-nitroquipazines

\begin{tabular}{|c|c|c|c|c|c|c|}
\hline \multirow[t]{2}{*}{ Compound } & \multirow[t]{2}{*}{$\mathrm{R}$} & \multirow{2}{*}{$\begin{array}{l}\text { Molecular ion } \\
\mathrm{M}^{+} m / z(\%)^{\mathrm{a}}\end{array}$} & \multicolumn{2}{|c|}{ Base peak $m / z$} & \multirow[t]{2}{*}{$m / z(\%)^{\mathrm{a}}\left[\mathrm{RNC}_{4} \mathrm{H}_{6}{ }^{+}\right]^{\mathrm{c}}$} & \multirow[t]{2}{*}{ Other ions $\mathrm{m} / \mathrm{z}$} \\
\hline & & & $\mathrm{R}^{+}$ & {$\left[\mathrm{RNC}_{3} \mathrm{H}_{5}^{+}\right]^{\mathrm{b}}$} & & \\
\hline 1 & n-Octyl & $370(10 \%)$ & - & 168 & $181(31 \%)$ & $43,56,70,125,156,166,202,214,216,271$ \\
\hline 2 & $n$-Dodecyl & $426(5 \%)$ & - & 224 & $237(29 \%)$ & $43,56,70,125,202,212,222,271$ \\
\hline 3 & Cyclopentylmethyl & $340(12 \%)$ & - & 138 & $151(70 \%)$ & $41,56,70,82,126,170,202,216,271,322$ \\
\hline 4 & Cyclohexyl & $340(20 \%)$ & - & 138 & $151(30 \%)$ & $56,83,112,126,156,196,202,214,314$ \\
\hline 5 & Benzyl & $348(17 \%)$ & 91 & $146(30 \%)$ & $159(30 \%)$ & $56,65,202,214,257$ \\
\hline 6 & Fluorobenzyl & $366(15 \%)$ & 109 & $164(40 \%)$ & $177(43 \%)$ & $56,83,202,214,257$ \\
\hline
\end{tabular}

${ }^{\mathrm{a}}$ In parentheses, the relative intensity

${ }^{\mathrm{b}}$ Fragment a from Fig. 1b

${ }^{\mathrm{c}}$ Fragment $\mathrm{b}$ from Fig. $1 \mathrm{~b}$ 
The ions at $m / z 216.076\left(\mathrm{C}_{11} \mathrm{H}_{10} \mathrm{~N}_{3} \mathrm{O}_{2}\right)$ correspond to the protonated fragments $\mathrm{c}$ or $\mathrm{d}$ (Fig. 1b) resulting from breaking of the piperazine ring. The ions of low intensity at $m / z 170$ originate from subtraction of the nitro group from ions at $m / z$ 216. Similar to the EI spectra, the ESI spectra of compounds 5 and $\mathbf{6}$ showed ions at $\mathrm{m} / \mathrm{z} 91$ and $\mathrm{m} / \mathrm{z} 109$ (Fig. 1b, fragments $\mathrm{f}$ and $\mathrm{g}$ ), which correspond to benzyl and fluorobenzyl substituents $\left(\mathrm{C}_{7} \mathrm{H}_{7}{ }^{+}\right.$and $\mathrm{C}_{7} \mathrm{H}_{6} \mathrm{~F}^{+}$, respectively). No negative ions of 6-nitroquipazines 1-6 were observed in the ESI mass spectra.

In both EI and ESI mass spectra, very intense peaks corresponding to piperazine ring fragmentation were observed. However, it should be noted that the very intense peaks in the EI mass spectra correspond to the R substituent connected to the piperazine $4^{\prime}$ nitrogen atom (Fig. $1 \mathrm{~b}$, fragments a and $\mathrm{b}$ ). Theoretical calculations of the charge distribution of the electron-deficient molecular ion of compound $\mathbf{3}$ (formed during EI) showed the highest positive charge on the N-4' nitrogen atom. On the other hand, in the ESI mass spectra peaks corresponding to charged nitroaminoquinoline (Fig. 1b, fragments $\mathrm{c}$ and $\mathrm{d}$ ) had high intensity. Calculations of putative protonation sites formed during electrospray ionization showed that highest theoretical stability was obtained with the N-1 nitrogen atom protonated (relative energy $197.370241 \mathrm{kcal} / \mathrm{mol}$ ), followed by protonation at the N-4' (relative energy $200.034900 \mathrm{kcal} / \mathrm{mol}$ ) and then protonation at the $\mathrm{N}-1^{\prime}$ (relative energy $229.024006 \mathrm{kcal} / \mathrm{mol}$ ) nitrogen atoms. That would thus explain the formation of charged fragments $\mathrm{c}$ and d (Fig. 1b).

In conclusion, EI and ESI mass spectra of new SERT inhibitors have been reported, and it was found that in EI the main fragment ions contained $\mathrm{R}$ substituents whereas in ESI they contained a nitroquinoline moiety. The results obtained show that the negative ions in EI may be quite stable when a nitroaromatic moiety is present in the molecule. Theoretical calculations of the stability of electron-deficient and protonated daughter ions may help in explaining the fragmentation pattern of molecular ions and the relative ion stability.

Acknowledgement This study was supported by grant PNRF-103AI-1/07 through the Norwegian Financial Mechanism.

Open Access This article is distributed under the terms of the Creative Commons Attribution Noncommercial License which permits any noncommercial use, distribution, and reproduction in any medium, provided the original author(s) and source are credited.

\section{References}

1. Kanner BI, Zomot E (2008) Chem Rev 108:1654-1668

2. Schlosss P, Williams DC (1998) J Psychopharmacol 12:115-121

3. Masson J, Sagne C, Hamon H, Mestikawy S (1999) Pharmacol Rev 51:439-463

4. Reizer J, Reizer A, Saier HH Jr (1994) Biochim Biophys Acta 1197:133-166

5. Ramamoorthy S, Bauman AL, Moore KR, Han H, Yang-Feng T, Chang AS, Gomapathy Y, Blakely RD (1993) Proc Natl Acad Sci USA 90:2542-2546

6. Kitayama S, Dohi T (1996) J Pharmacol 72:195-208

7. Wong DT, Perry KW, Bymaster FP (2005) Nat Rev Drug Discov 4:764-774

8. Tatsumi M, Groshan K, Blakely RD, Richelson E (1997) Eur J Pharmacol 340:249-258

9. Homberg JR, Schubert D, Gaspar P (2010) Trends Pharmacol Sci 31:60-65

10. Blier P, de Montigny C (1994) Trends Pharmacol Sci 15:220-226

11. Jones BJ, Blackburn TP (2002) Pharmacol Biochem Behav 71:555-568

12. Chilmonczyk Z, Kossakowski J, Nowak G, Wołosewicz K, Wolak M, Siwek A, Stachowicz K, Szewczyk B, Bojarski AJ, Sylte I, Gabrielsen M (2011) The inhibitor of serotonin reuptake, its application and the way of synthesis. Patent application no PL 394344.

13. Wavefunction (2003) Spartan'04. Wavefunction, Irvine

14. Yinon J (1982) Mass Spectrom Rev 1:257-307 